\title{
Desenvolvimento de um Sistema Web para Visualização de Imagens Microscópicas: Resultados Iniciais e Próximos Passos
}

\author{
Carlos José M. Olguín ${ }^{1}$, Rose Meire C. Brancalhão ${ }^{2,3}$, Marcos F. Schmitt ${ }^{1}$ e \\ Bernardo de Lima ${ }^{2}$ \\ ${ }^{1}$ Colegiado de Ciência da Computação - Centro de Ciências Exatas e Tecnológicas \\ (CCET) - Universidade Estadual do Oeste do Paraná (UNIOESTE) \\ Caixa Postal 711 - 85.819-110 - Cascavel - PR - Brazil \\ ${ }^{2}$ Colegiado de Medicina - Centro de Ciências Médicas e Farmacêuticas (CCMF) - \\ Universidade Estadual do Oeste do Paraná (UNIOESTE) \\ ${ }^{3}$ Colegiado de Biologia - Centro de Ciências Biológicas e da Saúde (CCBS) - \\ Universidade Estadual do Oeste do Paraná (UNIOESTE)
}

\{prof.olguin, rosecb, bernardo.arv\}@gmail.com, marcos.mfs@msn.com

\begin{abstract}
The optical microscope is a very important teaching tool in the teaching and learning of body tissues. However, such an instrument is not always available to study the teachings of undergraduate, graduate, and in particular in basic education. Thus, the creation of a Virtual Atlas Histologic, coupled with broad accessibility to the Internet, allow an alternative source of information on the construction of scientific knowledge. Unlike Atlas available in the literature which usually present the image in only one specific tissue increased, the Virtual microscope Histology proposed in this study will provide an image on progressive increases in order to simulate a visualization under a microscope. This article presents the current state of development of virtual microscopy.
\end{abstract}

Resumo. O microscópio de luz é um instrumento didático de fundamental importância nos processos de ensino e aprendizagem de tecidos corpóreos. Contudo, tal instrumento nem sempre está disponivel ao estudo nos ensinos de graduação, pós-graduação e, em especial, no ensino básico. Com isso, a criação de um Atlas Virtual Histológico, aliado a ampla acessibilidade da internet, possibilitará uma fonte alternativa de informações na construção do saber científico. Diferentemente dos Atlas disponíveis na literatura, que normalmente apresentam a imagem de determinado tecido em apenas um aumento, o Microscópio Virtual, proposto neste estudo, irá apresentar a imagem em aumentos progressivos, de forma a simular uma visualização no microscópio. Este artigo apresenta o estado atual do desenvolvimento do microscópio virtual e próximos passos. 


\section{Introdução}

O sistema web de visualização de imagens é uma ferramenta que se aplica a diversas áreas do conhecimento humano, como no ensino da biologia tecidual (histologia). Seu estudo é fundamental na área médica e se inter-relaciona com a bioquímica, a biologia molecular, a fisiologia, a anatomia, entre outras. Além disso, o conhecimento da biologia tecidual normal é essencial no reconhecimento de alterações advindas de patologias diversas [Kierzenbaum 2004] [Leboffe 2005].

Na histologia a análise microscópica de lâminas é possibilita a compreensão da organização morfológica de tecidos corpóreos; pois é microscopicamente que se pode visualizar como um órgão se organiza na realização de suas funções diversas [Leboffe 2005]. Entretanto, o microscópio de luz nem sempre se apresenta disponível, e os estudantes frequentemente se utilizam, nos estudos extraclasses, de Atlas de histologia.

Com o avanço da tecnologia da informação, é cada vez mais frequente o uso de Atlas histológicos disponíveis na internet. $\mathrm{O}$ ambiente virtual permite aos alunos acessarem os materiais em suas residências e bibliotecas, por exemplo, em horários mais convenientes [Gómez-Arbonez et al. 2004] [Buchanan et al. 2005]. Possibilita, ainda, difundir os conhecimentos a outros estudantes e profissionais da área das ciências biológicas e da saúde, democratizando o acesso à informação. Assim, a união de recursos tecnológicos e humanos, com a disponibilidade de ferramentas qualificadas para a aprendizagem, poderá resultar em inovações positivas nas estratégias e metodologias de ensino.

Neste trabalho, apresentamos o estado atual de desenvolvimento de um sistema web para visualização de imagens microscópicas da histologia humana em aumentos diferenciados, de 40X até 1.000X, o Microscópio Virtual de Histologia. Com o desenvolvimento deste sistema pretende-se contribuir de forma significativa com o processo de construção de conhecimento em histologia humana, além de propiciar a democratização do acesso à informação.

No trabalho foi utilizado o sistema gerenciador de conteúdo Joomla!, por ser uma ferramenta livre que oferece funcionalidades para o desenvolvimento de componentes novos, além de atender as necessidades técnicas do projeto.

\section{Material e Métodos}

Como outros CMS - Content Management Systems (Sistemas Gerenciadores de Conteúdo), Joomla! [North 2008] ajuda a minimizar um problema comum no desenvolvimento web, isto é, o custo para produzir e manter um site. Ao mesmo tempo, o conhecimento técnico necessário para construir um site não é trivial, o que faz, como consequência, que o usuário final do site fique na dependência de pessoas especializadas em mantê-lo. A proposta do Joomla! é diminuir, e muito, essa dependência.

CMS servem para ajudar a criar e manter uma página na web de forma eficaz. A maioria dos websites exige funcionalidades básicas como cadastro de usuários, edição 
de conteúdo, publicação de banners e propagandas, entre outras. Um CMS oferece funções prontas para realizar essas tarefas, e ainda pode expandir a capacidade de gerenciamento instalando componentes como, por exemplo, uma galeria de imagens.

Joomla!, além de ter todas as vantagens de um CMS, tem a característica de ter sido desenvolvido na categoria de Software Livre, o que elimina os custos com licenças de utilização do mesmo. O banco de dados utilizado por ele também é simples e livre, o MySQL pode ser facilmente encontrado na maioria, para não dizer na totalidade, dos servidores web. Uma limitação é que o visual do website (front-end) pode ficar comprometido pelo simples fato de que as posições dos templates para publicar o conteúdo nem sempre são flexíveis, o que significa que se deve ter um conhecimento avançado para adequá-lo.

Além dos motivos citados acima, que o Joomla! é livre e que utiliza MySQL como banco de dados, outros motivos foram levados em consideração para sua escolha. O primeiro deles é que o CMS Joomla! é um dos mais utilizados no Brasil e no mundo, perdendo apenas para o WordPress (Figura 1).

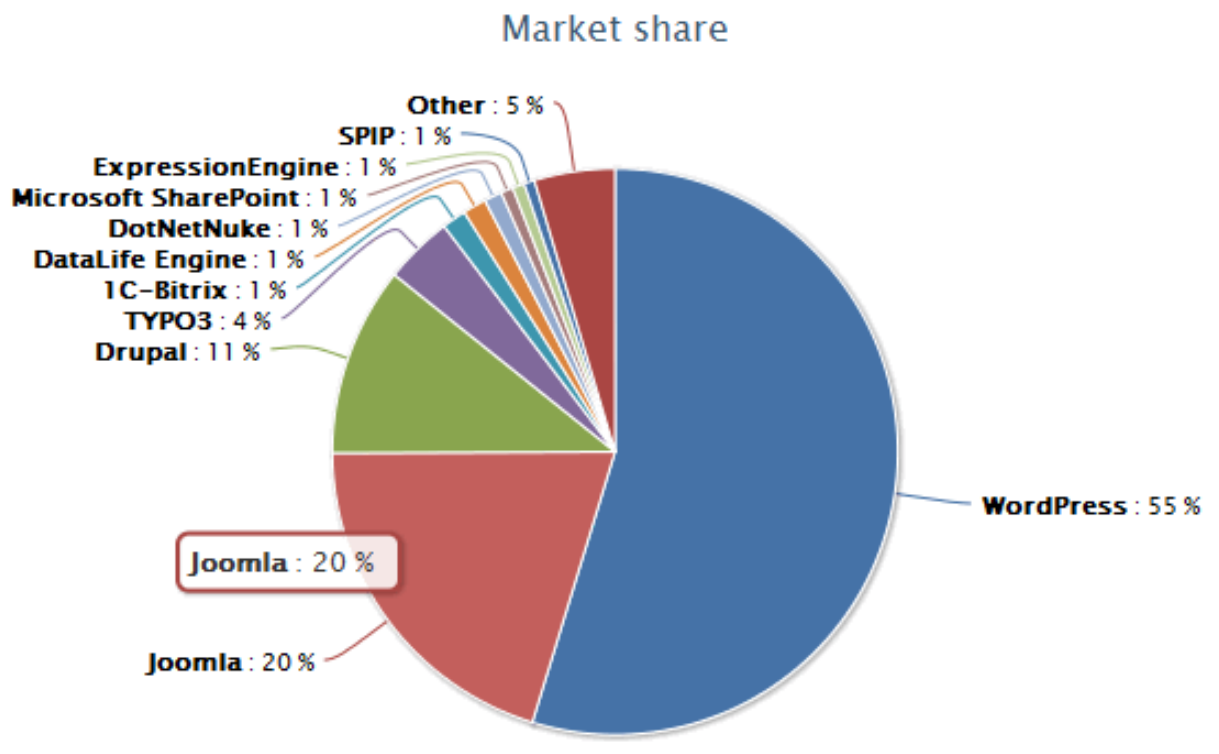

Figura 1. Market share de CMS.

Fonte: GAVICKPRO - Creative Joomla! Development Studio

Sendo o WordPress famoso pela facilidade na confecção de blogs e considerando que o nosso foco não era esse, nossos estudos se voltaram para o Joomla!, que tem a maior comunidade brasileira de CMS, com muitos fóruns e tutoriais para auxiliar na utilização do mesmo.

O Joomla! conta também com um diretório de extensões muito amplo, que pode ser acessado em http://extensions.joomla.org/, onde muitas delas são em português. Uma das extensões mais usadas é a Phoca Gallery, que conseguia atingir todos os 
requisitos do banco de imagens. Com ela se pode organizar as imagens em categorias e pastas diferentes, não somente para ficar mais organizado mas, principalmente, pelo motivo de que a visualização do site no front-end fica organizada conforme as categorias criadas no painel administrativo da galeria.

Então, se divide o banco de imagens em categorias e subcategorias conforme a necessidade do administrador das imagens, o qual não tem dificuldade nenhuma de mostrá-las no site com a organização que quiser.

O sistema web para visualização de imagens microscópicas (Microscópio Virtual) vem se desenvolvendo desde junho de 2010. O objetivo principal é apresentar o banco de imagens (foto-micrografias de tecidos corpóreos), juntamente com uma descrição da imagem mostrada. O banco de imagem, ainda que em construção, apresenta cerca de 300 imagens microscópicas, onde os tecidos são apresentados em aumentos progressivos de 40X a 1.000X. Dessas imagens, quatro foram selecionadas para cada tipo de tecido e então, foram descritas utilizando-se bibliografia adequada e atlas histológicos disponíveis na literatura.

O processo de desenvolvimento começou com o levantamento de requisitos do sistema. Entre os principais requisitos está a possibilidade de que pessoas autorizadas possam atualizar o banco de imagens. Este requisito foi o que determinou o uso de Joomla! que permite o cadastramento de usuários do sistema definindo permissões de uso.

O layout que o site Microscópio Virtual exibe hoje é fruto do uso de um template Weight Loss que tem sua distribuição gratuita baseada na licença GNU-GPL. Este foi desenvolvido pela ThemZa Free CMS Templates e pode ser encontrado na página deles (themza.com) ou senão com um link direto para ele que pode ser acessado em http://www.themza.com/joomla/weight-loss-template.html, mas vale ressaltar ainda que este template não foi escolhido pela descrição que está no site do desenvolvedor, ou até pelo propósito deste template, mas sim pelo design propriamente dito, pois contém a core que combina com a logo da UNIVERSIDADE, azul [ThemZa.com, 2010].

\subsection{Joomla! 1.5}

O Joomla! está na sua versão 2.5.6, mas desde a versão 1.6 está com mudanças significativas em relação ao Joomla! 1.5. O controle de acessos dos usuários está redefinido, uma das alterações é que agora o administrador tem mais controle sobre a página e não apenas sobre os artigos, assim ele pode editar, criar ou mesmo visualizar quando a página estiver em manutenção. Mas a maior mudança em relação a isso é que agora, nas versões acima de 1.6 podem-se criar grupos personalizados de usuários, ou seja, pode-se criar um grupo que acessa módulos específicos, e outros não, o que se chama Access Control List - ACL.

As categorias tem uma estrutura mais flexível. Agora pode-se criar subcategorias para que o conteúdo possa ficar mais organizado e dar mais liberdade de divisão para o editor ou administrador do web site. A capacidade de gerenciar conteúdos em várias línguas é outra mudança que chama atenção, não precisa mais de aplicações ou mesmo 
componentes de terceiros, como são conhecidos no Joomla!, para que as páginas possam ser acessadas em línguas diferentes.

Na versão 1.5 já existia a capacidade de agendar a data de início e fim da publicação de um artigo, mas agora se pode fazer isto também para módulos. A parte de fazer upload de imagens e outros arquivos também ficou mais fácil, pois se podem "subir" vários arquivos ao mesmo tempo e não mais somente um de cada vez. Outra vantagem é que um mesmo web site em Joomla! 1.6, ou superior, pode conter vários temas, ou seja, vários layouts em diferentes menus ou páginas.

Mesmo com todas as melhorias que as versões de Joomla! acima da 1.6 apresentam, para o desenvolvimento do nosso site utiliza-se ainda o Joomla! 1.5, pois essa é uma versão mais estável e que atende todas as necessidades da página do Microscópio Virtual de Histologia da UNIOESTE.

\subsection{MySQL}

MySQL é um sistema gerenciador de banco de dados relacional (SGBDR) baseado em SQL. Teve origem no final dos anos 90 e está em constante evolução. É um produto de código aberto que pode ser usado também, como o Joomla!, sob a licença GNU-GPL.

Uma das características que torna o MySQL um dos bancos mais utilizados do mundo é que ele pode ser executado em quase todas as plataformas de sistemas operacionais disponíveis hoje, dentre as quais se pode citar o Linux, o Windows e o Mac OS X.

Outro ponto importante para esse projeto, é que ele possui um vasto conjunto de bibliotecas disponíveis nas mais variadas linguagens de programação existentes, incluindo PHP, que é a linguagem utilizada para o desenvolvimento de Joomla!, Java, $\mathrm{C}++\mathrm{e}$ outras.

Finalmente, o gerenciador tem uma consulta rápida o que é imprescindível para uma aplicação web.

\subsection{Phoca Gallery}

O Phoca Gallery é uma galeria de imagens desenvolvida para Joomla!, ou seja, é um componente que inclui módulos e plug-ins, que permite os usuários visualizar imagens ou vídeos em vários estilos diferentes.

Esta galeria é totalmente gratuita e de fácil utilização, o administrador das imagens do Web Site pode criar diferentes categorias e galerias para sua página, sendo assim, as imagens podem ser facilmente divididas em grupos e exibidas em diferentes menus ou submenus, ou ainda ser exibidas em módulos.

\section{Resultados e Discussão}

Diante do avanço tecnológico, da ampla acessibilidade da população à rede mundial de computadores e do acesso à educação para considerável parcela da população, o Microscópio Virtual veio somar às propostas de complemento do estudo de Biologia 
Tecidual, dispondo de um meio virtual para o saber científico dos tecidos corpóreos. Após as fases iniciais do projeto, nas quais o material doado foi processado por técnicas histológicas de preparo, as imagens foram obtidas, através de fotomicroscopia, identificadas com legendas, digitalizadas e dispostas na página do Microscópio Virtual na rede mundial de computadores, enfim, pode-se disponibilizar o link de acesso às comunidades acadêmicas para que discentes, docentes, e demais interessados em Biologia Tecidual, tivessem acesso ao banco de imagens obtido até então.

A estrutura do sistema atende a classificação de tecidos conforme a necessidade. Isto é concretizado através de um menu que se apresenta ao usuário (Figura 2a). Selecionando uma das opções do menu se apresentam as imagens do tecido selecionado em aumentos progressivos de 40X a 1000X (Figura 2b). A seleção de uma das miniaturas provoca a apresentação da imagem ampliada juntamente como uma descrição da mesma (Figura 2c).

Os passos seguintes são a melhoria da interface, visando aprimorar a usabilidade do mesmo, considerando também a promoção da facilidade de acesso por pessoas com visão reduzida e utilizadores do leitor de tela DOSVOX. Adicionalmente, precisa ser feito o trabalho de complementação das imagens e dos textos associados no banco de dados do sistema, assim como realizar as alterações necessárias no template para poder adicionar novas entradas no menu de tecidos.

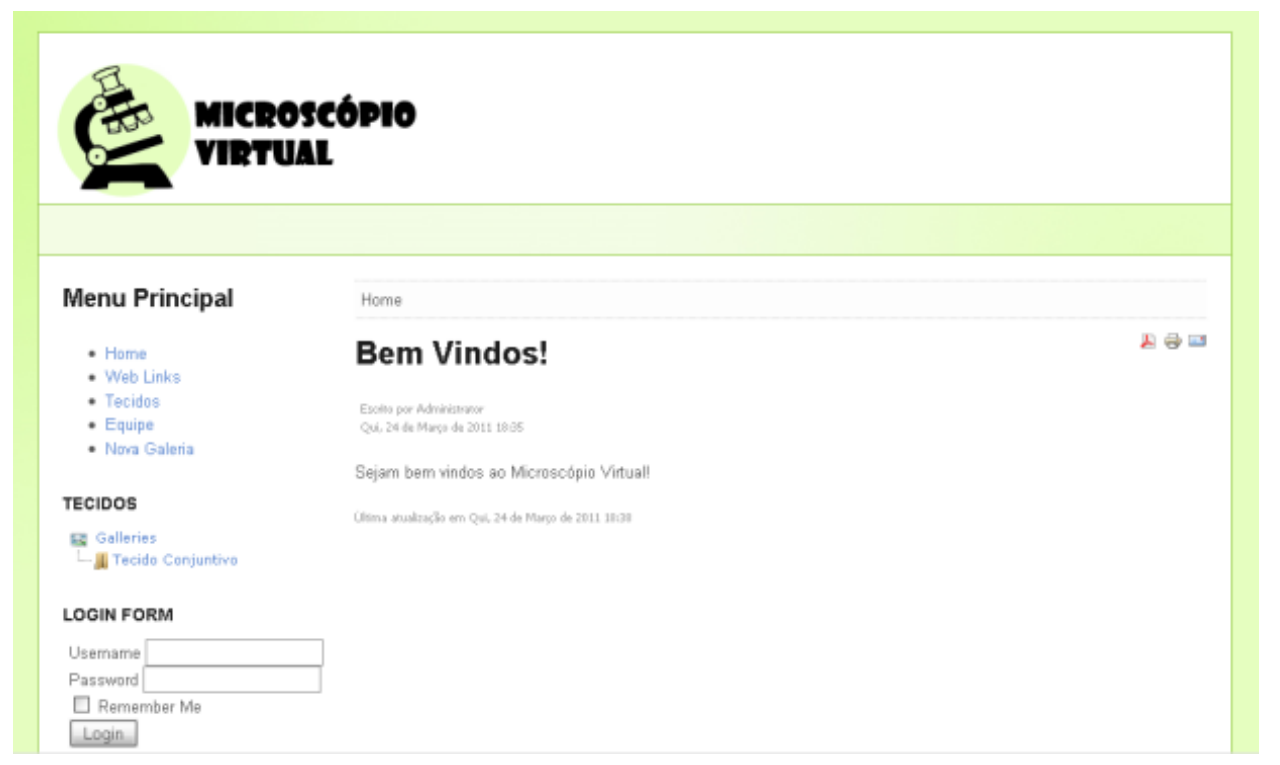

(a) 


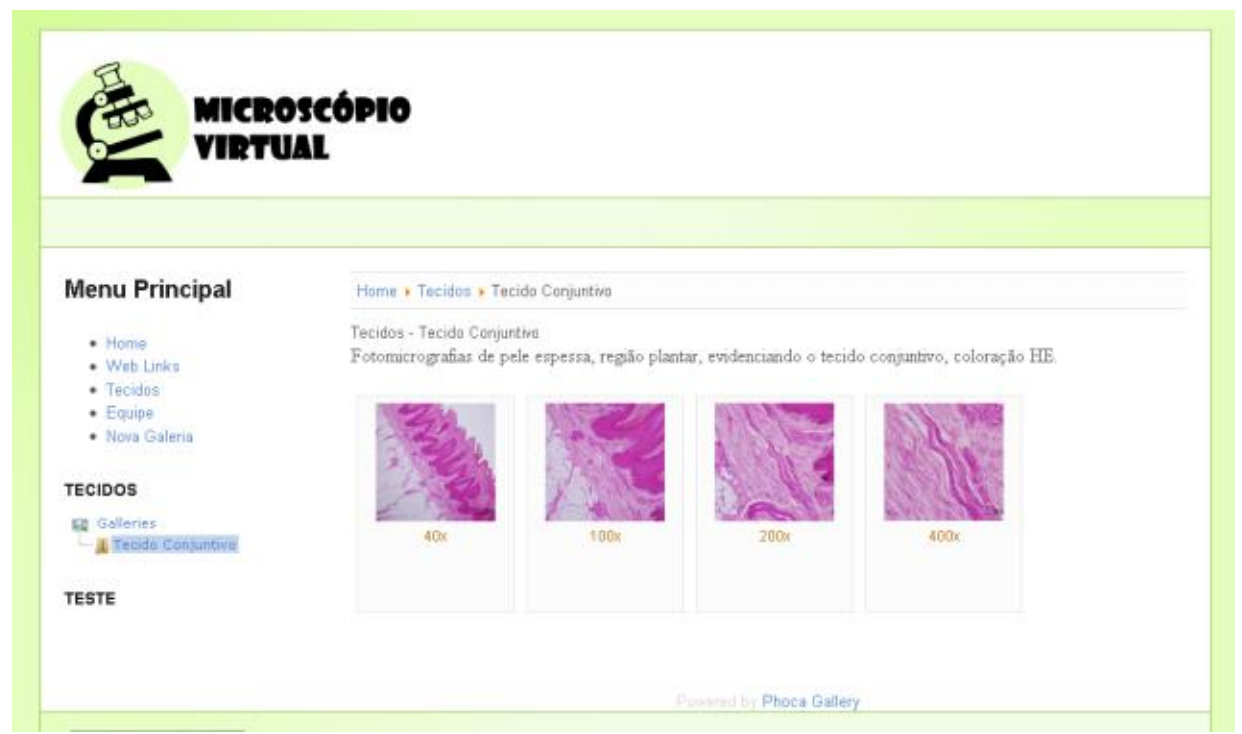

(b)

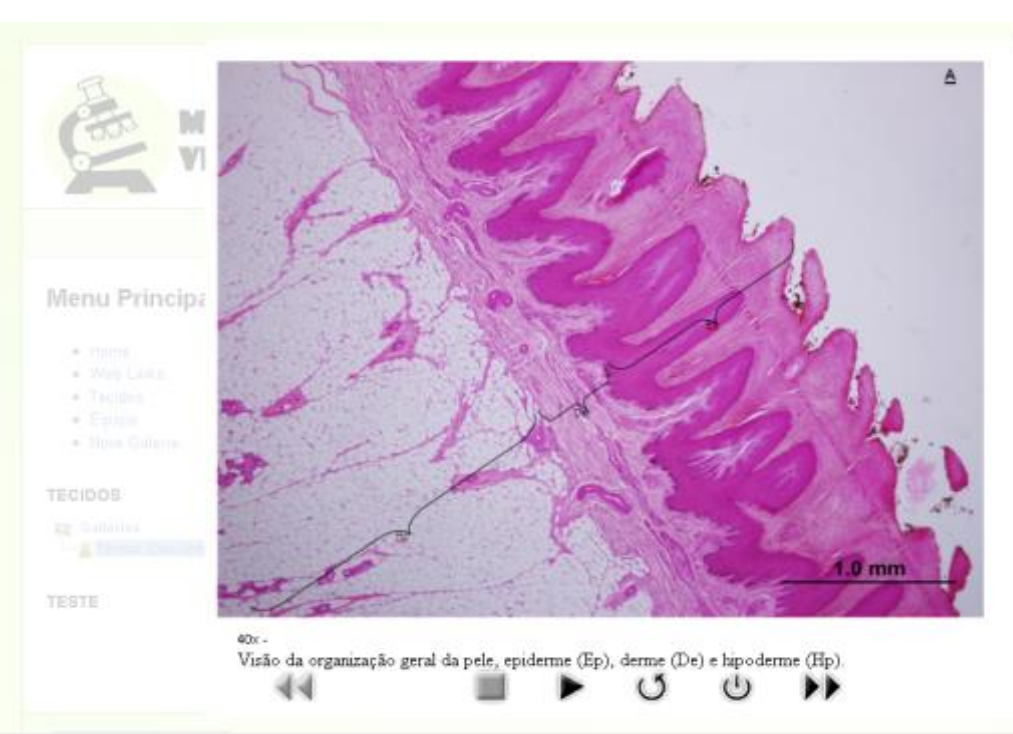

(c)

Figura 2. Telas da primeira versão do sistema.

Como se pode observar acima, na Figura 2, a primeira versão do sistema não se preocupava com o layout que tornaria a visita do estudante mais agradável.

Na versão que se encontra o Web Site, que já está sendo utilizada há três meses na Universidade Estadual do Oeste do Paraná, nota-se uma significativa alteração quanto a esta preocupação.

Como se observa na Figura 3, se tornou mais agradável a visita à página e mais fácil a visualização das imagens que estão separadas em suas respectivas galerias. 


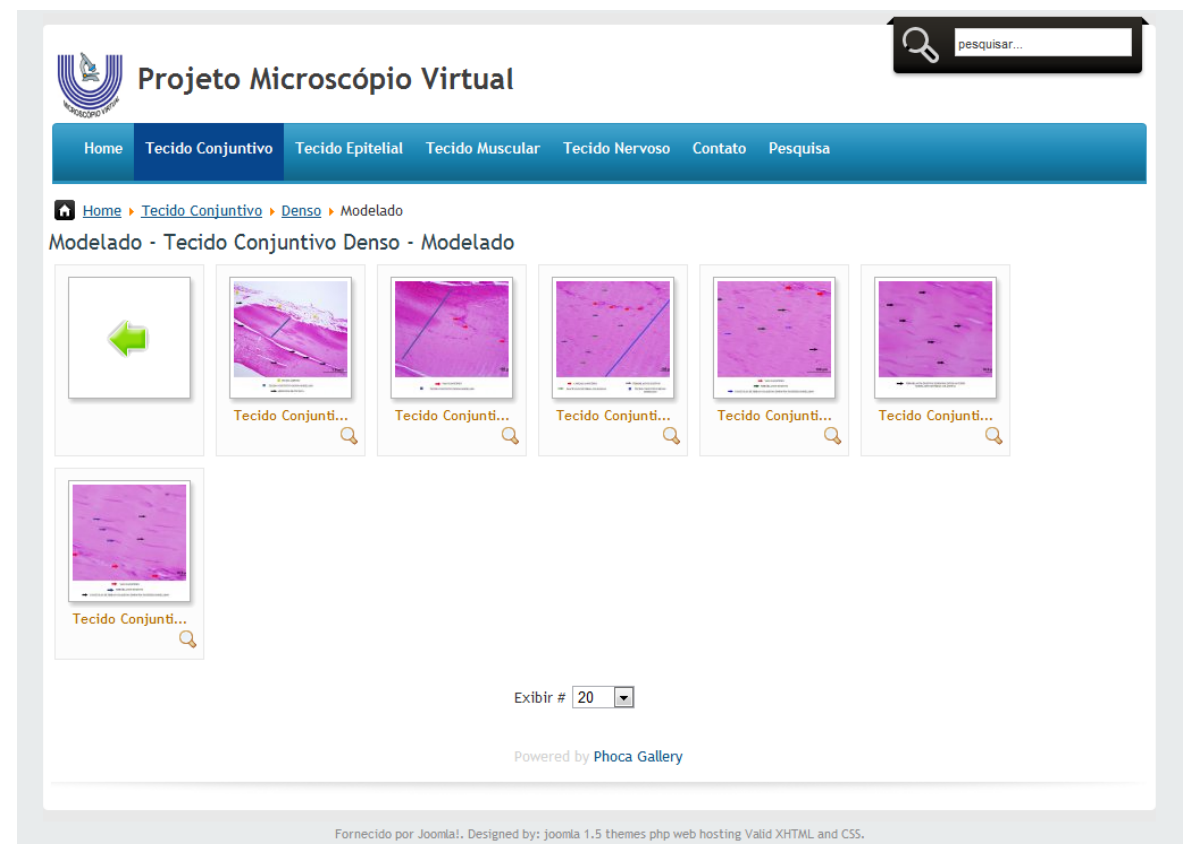

Figura 3. Tela de visualização de uma galeria.

É importante salientar que a formação do banco de imagens tinha como proposta inicial atender os alunos de graduação, pós-graduação e docentes da Universidade Estadual do Oeste do Paraná e seus Campi. Com o decorrer das atividades do projeto, porém, concluiu-se que seria importante dividir com os demais interessados no assunto o material obtido nessas fases iniciais. A partir disso, o endereço eletrônico do Projeto Microscópio Virtual tornou-se um objetivo importante e, atualmente, é realidade.

Em 15 de Junho de 2012, o endereço eletrônico do Projeto Microscópio Virtual tornou-se disponível para o amplo acesso através da rede mundial de computadores. Até a presente data (29/09/2012), o endereço já foi visitado por cerca de 67.750 pessoas, com uma média de 4600 visitas por semana, o que reforça a tese de que o presente projeto é de suma importância como forma alternativa de saber científico, reforçado pelo objetivo de ser um instrumento didático de fundamental importância para os processos de ensino e aprendizagem de biologia tecidual.

Finalmente, é interessante mencionar que dentro deste site há opção para contato com os administradores (opção "Contato"), bem como para sugestões e críticas (opção "Pesquisa"). Receberam-se diversos mails com sugestões e comentários. Dentre eles podemos citar, como exemplo: "Ótimo site. Me ajudou bastante, imagens autoexplicativas, continuo estudando mesmo estando longe do microscópio. Parabéns."; "Acho que o site poderia conte imagens dos órgãos sensoriais, como por exemplo papilas gustativas e epitélio sensorial do olho. Também seria legal ter um panorama geral com divisão por sistemas, como digestório por exemplo.”. Estes comentários nos apresentam novos desafios, isto é, pensar na disponibilização de outros sistemas, órgãos e demais tecidos; a organização do site em um mapa, permitindo ao visitante uma visão geral do site, antes de procurar especificamente um tema; e ainda, a organização das 
informações em forma de um panorama geral, que dê informações a partir de um Sistema, como por exemplo, Digestório. É interessante mencionar que todos os visitantes do site que acessaram o link "pesquisa", ao serem questionadas sobre o que acharam do site e se recomendariam o mesmo para outras pessoas responderam 'otimo' e 'sim' respectivamente. Além destes comentários recebemos elogios de visitantes de outros países, o que reforça a importância e o alcance de uma novidade tecnológica tão empreendedora como este site.

\section{Conclusões}

Neste trabalho apresentamos o estágio de desenvolvimento de um sistema web para visualização de imagens microscópicas em aumentos diferenciados de até 1000X, o microscópio virtual de histologia. Acreditamos que este sistema irá auxiliar estudantes de graduação, professores e profissionais da área de Ciências Biológicas e da Saúde. Cabe ressaltar o papel motivador das imagens, trazendo conteúdos significativos e compreensíveis, além de métodos adequados, o que certamente auxiliará no processo de ensino e aprendizagem.

O Microscópio Virtual já está atingindo, com certeza, seu objetivo geral e atingiu muitos dos seus objetivos específicos. Cabe salientar que ainda há muito trabalho a ser realizado. Boa parte deste trabalho surgirá, sem duvida alguma, das sugestões de melhorias da página e solicitações para colocar outras imagens, sugestões estas recebidas a partir do link "Contato" do site.

\section{Agradecimentos}

Ao MEC/SESu/DIFES, à PROEX-UNIOESTE, à UNIOESTE e aos avaliadores do artigo.

\section{Referências}

Buchanan, M. F.; Carter, W. C.; Cowgill, L. M.; Hurley, D. J.; Lewis, J. S.; Macleod, J.; Melton, T. R.; Moore, J. N.; Pessah, I.; Robertson, T. P.; Smith, M. L.; Vandenplas, M. L. (2005) Using 3d animations to teach intracellular signal transduction mechanisms: taking the arrows out of cells. Journal of Veterinary Medical Education n.32, p. 72-78, 2005.

GavickPro - Creative Joomla! Development Studio, Wappalyzer Stats about CMS including Joomla. Acessado < http://www.gavick.com/magazine/wappalyzer-andcms-including-joomla.html $>$, em 27 de Setembro de 2012.

Gomez-Arbones, X.; Ferreira, A.; Pique, M.; Roca, J.;Tomas, J.; Frutos, J. L.; Vinyas, J.; Prat, J. (2004) A cardiological web as an adjunct to medical teaching: Prospective analysis. Med Teach. n. 26, p 187-189, 2004.

North, B. M. (2008) Joomla! - Guia do Operador - Construindo um bem sucedido site Joomla! Rio de Janeiro: Alta Books, 2008.

Kierzenbaum, A. L. (2004) Histologia e Biologia Celular. Uma Introdução à Patologia. 
Rio de Janeiro: Elsevier, 2004.

Leboffe, M. J. (2005) Atlas Fotográfico de Histologia. Rio de Janeiro: Guanabara Koogan, 2005.

Themza.com, Weight Loss template for Joomla! 1.5. Acessado em $<$ http://www.themza.com/joomla/weight-loss-template.html $>$, em 23 de Agosto de 2010 . 